\title{
Inspiring Women Undergraduates
}

\author{
Hannah M. Dee \\ GIPSA lab, INPG \\ 961 rue de la Houille Blanche, BP46, 38402 \\ Grenoble, France \\ hmd@hannahdee.eu
}

\author{
Roger D. Boyle \\ School of Computing \\ University of Leeds \\ Leeds, LS2 9JT, UK \\ roger@comp.leeds.ac.uk
}

\begin{abstract}
This paper describes the conception, motivation, organization, and evaluation of a national, one-day event for women students of computing: the BCSWomen Lovelace Colloquium. The aim of this paper is to demonstrate that such events have value for women students of computing. We hope to show that through introducing these undergraduate women to high profile role models we can inspire them, and that through providing the students with a forum for presenting their own work, we can be inspired by them ourselves. We believe this is a successful and economical model for an event which could be re-used in other countries or regions.
\end{abstract}

\section{Categories and Subject Descriptors}

K.3.m [Computers and education]: Miscellaneous

\section{General Terms}

Human factors

\section{Keywords}

Women in computing, Gender issues, Motivation

\section{INTRODUCTION}

This paper describes the conception, motivation, organization, and evaluation of a national, one-day event for women students of computing which is now established as an annual event. The problems facing women in computing and related disciplines are well-documented, with the proportion of women in technical roles and studying technical subjects hovering around $15 \%$ in the UK[7]. This gender imbalance is linked to recruitment problems, drop-out rates (the so called 'leaky pipeline' $[4,6]$ ), a perception of computing as a macho subject, and isolation for those women who do choose to work or study within the field.

Attempts to investigate and to address these problems have been initiated in many countries and internationally.

Permission to make digital or hard copies of all or part of this work for personal or classroom use is granted without fee provided that copies are not made or distributed for profit or commercial advantage and that copies bear this notice and the full citation on the first page. To copy otherwise, to republish, to post on servers or to redistribute to lists, requires prior specific permission and/or a fee.

ITiCSE'10, June 26-30, 2010, Bilkent, Ankara, Turkey.

Copyright 2010 ACM 978-1-60558-820-9/10/06 ...\$10.00.
The ACM (Association for Computing Machinery), in conjunction with the WGBH Educational Foundation, have been investigating in depth the perception of computing with their "New Image for Computing" project [1]. The BCS (British Computer Society) with trade body Intellect and government office e-Skills have carried out a major survey in the UK looking at the representation of women across computing careers and education [7]. Various projects offer grant support to women in technical fields (e.g. Anita Borg fellowships from Google [3], or the Society of Women Engineers [2]). Networking organisations exist to support women at the level of individual companies (BT Women's network, Google women engineers) national (e.g. BCSWomen in the UK; Frauen Inform in Germany), and international (e.g. Girl Geek Dinners, IEEE women in engineering, ACM-W) levels.

Another type of intervention is that of the conference or colloquium. These events bring together women working in or studying computing and serve the purpose of providing networking opportunities and exposure to role models. This paper describes the conception, aims and evaluation of just such an event: the BCSWomen Lovelace Colloquium (referred to hereafter as The Lovelace for brevity). This is an UK annual event aimed at an often neglected part of the community: undergraduate and taught Masters students. It is now entering its third year.

\subsection{Related events, their aims and impact}

This section provides a brief overview of existing events with a similar aim to ours. We emphasise UK events here as the Lovelace is aimed at a UK audience.

The Grace Hopper: This is the largest women-in-technology event in the world, and occurs annually. It is aimed at industry, students, academics, and high school teachers. Last year's event had over 1500 attendees.

The London Hopper Colloquium: This is a one-day event for UK based women postgraduate research students, held in London each spring. Last year's had 60 attendees

W-tech: Held for the first time in 2009, W-tech was conceived as a UK-based event along the lines of the USA's Grace Hopper, but oriented strongly towards the workforce with multi-track professional development sessions throughout the day. The 2009 event had 700 attendees. Whilst it was clearly viewed as a success 
by attendees and organisers, various circumstances ${ }^{1}$ mean that it is unlikely this event will be repeated in 2010 .

Girls and Gadgets: Aimed at school-aged girls in the North East of the UK, this is a one-day event aimed at getting teenaged girls interested in technical questions. In 2009, this event attracted around 200 girls from 20 schools. Similar events aimed at school-aged girls occur in many other regions.

Computer Science Research conference 2008 [9]: This event was aimed at UK students of computing - not just women - and was held in Cambridge in December 2008. nearly 100 students attended, of whom less than $15 \%$ were women. The aim of this event was specifically to get students of computing interested in the questions raised by computer science research, and was driven by the decline in UK applications for $\mathrm{PhD}$ positions. This event took place over 3 days and involved residential accommodation for students and accompanying staff from universities throughout the UK. This event was not held in 2009, and at the time of writing it is unclear whether it will occur in 2010.

This list is not exhaustive - there are many regional events, and events put on by specific companies (e.g. the Google Anita Borg Scholarship retreat, Microsoft DigiGirlz). The existence of events for women, coupled with much anecdotal evidence, is testimony to their worth. However, there is precious little provision for those between high school age and membership of the profession: Camp's 'pipeline' [6] is known to leak women at graduation, and it is this gap we set out to fill.

It is worth noting here that many of these events rely heavily on sponsorship from industry, and that the current economic climate has naturally affected the level of support available for them. In particular, the more extravagant conferences can require massive amounts of funding and this is much harder to raise in a recession. An overview of the financial aspects of funding the Lovelace event will be presented in Section 3.

\section{THE AIMS OF THE EVENT}

The Lovelace event has three main aims:

1. Educationally, to provide an opportunity for women students to present and discuss their own work;

2. To provide exposure to potential role models by having speakers who are (highly placed) successful technical women from academia and industry;

3. To provide a space in which students can network with other students from across the UK, with academics from outside their own university, and with industry representatives.

This section considers each of these aims in turn and describes the motivation behind choosing these for the event and the ways in which these are realised.

\footnotetext{
${ }^{1}$ Partly surrounding the current economic situation, but exacerbated by the need to move the date from February to July when a last-minute severe weather front struck London closing all transport links.
}

\subsection{Educational}

A great part of students' university education lies outside formal learning and encourages their enculturation and maturity as practicing scientists $[5,13,16]$. By its nature, this is harder to identify and to assess, but represents for most professional graduate futures something as important as exams. Employers seek the 'rounded individual', and laboratories seek innovative scientists versed in their procedures. In nearly all computing programmes worldwide these issues are addressed - in part at least - through the conduct of project work. A sizeable piece of independent final-year work is seen as a way of practicing advanced knowledge and skills within the framework in which computer science is 'done', usually culminating in a report and perhaps demonstration of practical achievement [8].

Normally this is a process conducted within a Department; while students gain the benefit of close academic interaction with a supervisor, they do not usually find their work exposed to those outside their institution, nor see the achievement or ability of those who are peer in the discipline, but unknown to them. We suggest that presenting to the broader peer and professional audience brings a number of benefits;

- It will require them to see their own work in a broader context than their own Department.

- It will require them to encapsulate clearly and succinctly what they have done, and where they have contributed.

- It will provide first hand experience of academic presentation in a way difficult to simulate in the closed community of one Department where the work is being done primarily for academic credit rather than as scientific contribution. For example, receiving comments and insights from unexplored areas of computing.

- It will give the opportunity for comparison of one's ability and practice with peers in a primarily noncompetitive manner.

As ever, there are problems of logistics and scale, but we suggest that a poster competition is a good format for this experience. The poster is an accepted medium for the succinct presentation of scientific ideas and contribution; it can be produced to high quality at modest cost; it lends itself to simultaneous exhibition with a number of others; and it rehearses the skills of presentation that are part of graduate qualification. Where programmes do not already require something of this nature, a dissertation (normally standard) would provide the raw material, and so it would represent minimal overhead for the student.

We propose therefore an invitation to students to attend a poster session in which they present 'their project work'; this is not tightly circumscribed and leaves the door open for students not in their specialist final year to present on work they have done or material of direct interest to them the aim is to provide direct experience of encapsulating and displaying their work and thoughts, and to see the direct experience of others who are their peers but not colleagues, in a congenial atmosphere.

We learned a side-effect of mounting such an event that may seem patronizing but we consider nonetheless to be important. For most of the students we hosted, this was their 


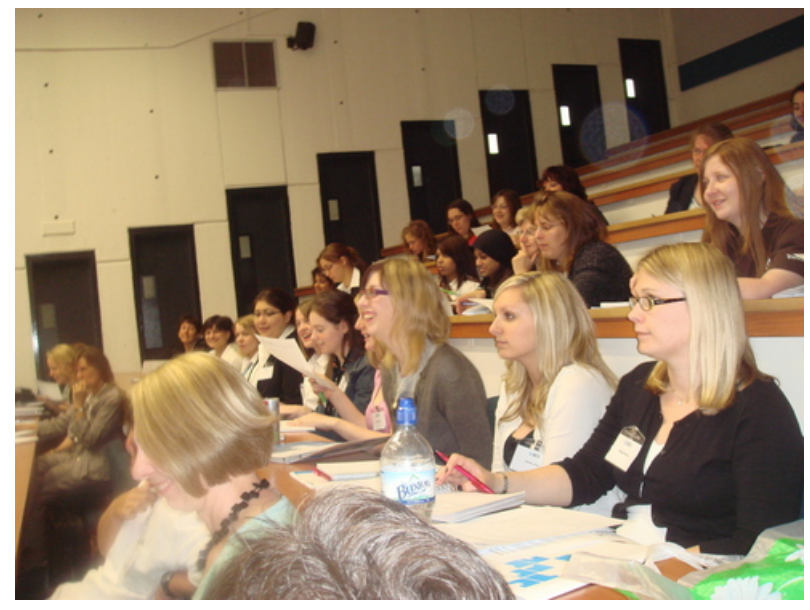

Figure 1: Part of the audience during the keynote address, 2008

first experience of an 'event' outside their own institution. We consider the merits of professional networking elsewhere, but would stress the benefits gained from young individuals organizing their own travel to a new town; locating a strange institution; bringing and displaying their materials; learning the ropes of expenses and subsidy; perhaps overnighting. We had overlooked that for most, these were new and sometimes daunting experiences that cannot be learned in a classroom, but are obviously necessary in the practicing professional. This issue was addressed in post-event feedback - an example is in Section 4.1.

\subsection{Role models}

Psychological research suggests that women respond better to female role models [10] and yet within computing the vast majority of "stars" are men, the vast majority of lecturers are men, invited speakers tend to be male, and students are predominantly male. There have been initiatives recently to try and address this in the context of "tech conferences", however, perusing the top-10-geeks lists in the media suggests that they are predominantly if not entirely male $^{2}$. Thus one of the major aims of the Lovelace event was to present students with speakers from both industry and academia who were successful women. Details of the programme and speaker selection will be covered in Section 3 but the principal guiding our choice of speakers was that they were to be successful, technical, women and talking about technical material.

\subsection{Networking}

The value of networking in the creation and sustenance of a career is well recognised, and this can be problematic for women in a male dominated industry[12]. However for students from minority groups there is an additional value to networking within that minority which can often be overlooked: this is the value that comes from realising that 'you are not alone'. It may seem that women in computing are no longer isolated, thanks in part to the various initiatives outlined earlier, but the penetration of these initiatives is

\footnotetext{
${ }^{2}$ Examples include [15, 11]; the number of women on these lists is very small. The existence of lists such as the 'hottest top-10 geek-girls' serves in a sense to underline our point.
}

\begin{tabular}{|l|l|}
\hline Component & Source \\
\hline Venue & \\
Hall/Lecture theatre & University \\
Poster contest space & University \\
Social venue & University bar \\
Web presence & University \\
\hline $\begin{array}{l}\text { Travel } \\
\text { Speaker travel }\end{array}$ & Donated/voluntary \\
Student travel & Covered by sponsorship \\
\hline $\begin{array}{l}\text { Speakers } \\
\text { Speaker time }\end{array}$ & Donated/voluntary \\
\hline $\begin{array}{l}\text { Catering } \\
\text { Lunch }\end{array}$ & Covered by sponsorship \\
Reception (evening) & Covered by sponsorship \\
\hline $\begin{array}{l}\text { Poster contest } \\
\text { Reviewing abstracts }\end{array}$ & Volunteers \\
Poster printing & Responsibility of individ- \\
Judges & ual students \\
Prizes & Volunteers \\
\hline
\end{tabular}

Table 1: Breakdown of the elements of the event along with the funding body or source: it is worth noting that without the institutional goodwill indicated by donations of lecture theatre and poster space, the event would have been difficult to run

far from complete. Academic Departments with just two or three women students are not unusual. Similarly, Departments with few or even no female staff (other than administrative support) still exist. It can be instructive to hold conversations with the female students in these environments.

\section{ORGANISATIONAL DETAILS}

This section provides an overview of the program design decisions we made when setting up the colloquium, and an indication of requirements to aid others in constructing similar events. The event attracted 80 registrants in the first year and 110 in the second year, of which about 30 each year were fully funded poster contest entrants. The remaining registrants were non-presenting students, interested postgraduates, university staff ${ }^{3}$, and industry representatives. In 2009 we opened the event up to interested 17 and 18 year old women from local schools, and will do the same in 2010. 2008 was entirely female; 2009 had one male speaker (the President of the British Computer Society who opened the day with a short welcoming message), a visiting male academic who had accompanied three presenters, and one male undergraduate who had come along to support his partner.

\subsection{Practicalities and requirements}

Simply put, the requirements for staging an event such as the Lovelace are corporate support in the form of sponsorship and speakers, a supportive university in which to hold it, and 'on the ground' enthusiasm. Table 1 presents rather more detail about the way in which the responsibility and cost has been borne by corporate sponsors, university hosts, and volunteers.

By far the greatest cost borne from sponsorship was that ${ }^{3}$ Some institutions chose to send an accompanying member
of staff with their undergraduates 
of student travel: we have paid transport costs for all poster contest entrants. This outlay was minimised by requiring students to research routes and find discount or advance purchase tickets for train, coach or plane. Those requiring an overnight stay were advised to book into a specific discount hotel in the city centre with whom we had arranged a discount. Students were asked to check with the organisers before paying for tickets: whilst this introduced an administrative overhead it served to ensure that they were finding the most economic means of transport. We have in this way managed to transport more than 30 students across the UK to the event for around $£ 1,200$ two years running, with up to half of these spending at least one night. Additional sponsorship funding will enable greater numbers of funded students to attend the 2010 event.

The total approximate cost of each event held so far has been $£ 2,000-2,500$. We regard this as a very modest sum. This was raised without difficulty by approaching sponsors. Income has increased monotonically over the three years of the event - there is no doubt that a successful track record aids fundraising.

\subsection{Program design}

The program consisted of a keynote talk from a highprofile woman, four technical talks (two from industry and two from academia), a poster contest for the students to display and discuss their own work, and a panel session at the end of the day allowing the students to ask detailed questions about careers and general women-in-computing issues. The panel session includes some of the earlier speakers and a representative from a high-tech recruitment agency. The day concludes with an informal networking opportunity in the form of a "social", held in the students' union bar with limited drinks and snacks provided via sponsorship. By this point, the students have interacted with each other and the speakers during coffee breaks, lunch, poster contest and panel session, and so we found there was no need for structured networking or ice-breaker activities.

The technical program was designed to show students the kind of work women professionals were doing in both industry and academia; whilst some discussion of women-in-tech issues was expected (and encouraged during the keynote), we insisted that the main talks were "about the technology, not the women". Other than this criterion, the content of the talk was entirely the choice of the speaker, allowing them to select topics that interest and enthuse them. The technical subjects have ranged from data mining biofeedback information (taken mostly from people on roller-coasters) to userinterface design for mobile YouTube. We found that when approached, technical firms were keen to get involved with the event and indeed many have existing initiatives expressly to support and encourage the recruitment of women. From industry, we have so far attracted speakers from Google, Microsoft and IBM, and it is anticipated that technical women from some of these companies will speak at the 2010 event. From academia, we have had women professors and researchers from a range of UK universities.

\section{EVALUATION AND EXPERIENCES}

The clearest indication of the success of this event is the way in which the initial pilot in 2008 has become an annual event. Sponsors, student attendees and their home institutions showed such enthusiasm it was agreed to hold the 2009 event at the same institution as 2008. Due to staff moves, another host was needed for 2010, and two institutions volunteered. Thus we have venues agreed for both 2010 and 2011 (Cardiff and Birmingham).

The student attendees in 2008 came from more than 20 different universities, and 26 universities sent students to the 2009 event. Interestingly, nearly every university represented at the 2008 event also had students attending the 2009 event, which suggests to us that enthusiasm for the day had travelled back to the students' home institutions.

Poster contest entrants were selected based upon short (250 word) abstracts submitted and reviewed a few months before the event. Thus far we have been able to fund transport and accommodation costs for all women who submit an abstract at the appropriate academic level (and who are studying at UK institutions). The event is also open to students who do not wish to submit abstracts and produce posters, however these attendees do not receive the travel cost support. It is worth noting that the support for the event is high in some UK universities, with several nonpresenting students receiving travel assistance funded by their home institution. One of 2008's non-presenting students returned in 2009 to enter the poster contest (and won a prize).

\subsection{Quotes from attendees and university staff}

Only those at the events will be able to bear testimony to the powerful 'feelgood' sense they generated, although evidence is in the very small numbers who left to catch transport early, and in the very high numbers who remained for the networking and social evening event. More tangibly, a number of totally unsolicited emails were received later, sent spontaneously by attendees and their home institutions. Just a few examples will serve to illustarte their tone,

Just wanted to send a wee message to THANKYOU so much for organising the Lovelace Colloquium. I had a fantastic day and was made to feel really welcome. - one of the student attendees

The Lovelace event has had a very positive impact here, part of which seems to have been the appointment of our most senior female academic as a kind of "women's officer". - the tutor of a student attendee

Just wanted to say thanks for looking after $X$, she was a bit nervous going down to spend a day with computer scientists, but came back high as a kite - and not just because she won a prize ... she thought the talks and the other posters were really interesting and more wide-ranging than she expected. She also said the day was brilliantly organised, that there was a friendly atmosphere and a lot of discussion - the tutor of a student attendee

Many thanks for inviting us to participate in this event! I thought it was an excellent day, with quality speakers and a good standard of students attending. Congratulations! - one of the sponsors

\subsection{Room for improvement}

Whilst we are convinced that the events held in 2008 and 2009 were successes there remains some room for improvement. Attracting students from 26 different universities is an achievement, but one that can be bettered, and for 2010 we are working on improved publicity and hope that this will go some way towards extending the reach of the day. The inclusion of 17 and 18 year-old students from local schools 
is also something we wish to extend as this is known to be a critical time in 'pipeline leakage' [6]; there are several obstacles to this, however, the largest of which is the very low numbers of women studying computing at advanced level in UK Schools. In 2009, seven high school students registered for the event but only two made it on the day, and this suggests to us a further obstacle to school-level attendance: it can be a very daunting thing for a 17 -year-old to travel to a new, large university to interact with university students. It has been suggested that we arrange a "big-sister-littlesister" system where the undergraduate women are paired with the school students to make this a more feasible aim. The 2010 organisers are also investigating options for assisted transport (for example, a minibus) to help transport local high-school students.

\section{CONCLUSIONS AND FUTURE PLANS}

We have presented a format for an undergraduate event that meets three objectives: it gives greater substance to their (potential) professional standing and qualification; it provides an opportunity for networking with peers and probable future colleagues; and it provides first hand experience of hearing and speaking with role models of considerable seniority. The second and third objectives are primarily in favour of the badly under-represented female community.

We have outlined the organization and funding of such an event, demonstrating that it can be mounted successfully at modest cost: that it has run twice is testimony to the success of the format, especially as it will run again annually in future on a peripatetic basis with an established funding regime.

Feedback from the participants has been wholly positive and in many cases insightful and stimulating, making the holding of the event its own reward. Significantly, the major organizations and companies that came on board were also, throughout, wholly positive in their desire to participate very tangibly. The Colloquium's profile is high within many influential bodies. We therefore feel that this format is feasible, productive, and reproducible. We have recently discovered that academics and students from the University of Delft in the Netherlands may travel to the 2010 event, with the aim of seeing whether it can be replicated there.

Such an event hinges on two things: the hosting institution must be keen to participate, but experience suggests this is not problematic - most Department Heads will happily provide accommodation and other wheel-oiling for such an event. More key is the need for 'on the ground' enthusiastic goodwill ... individuals happy to give their time to see it happen. Of course all events, howsoever organized or structured, have this as a prerequisite for success, but our anecdotal view is that for this now annual event, the ratio of benefit to input effort is very considerable. To paraphrase, many sponsors will say 'Great idea, how can I help', but few will ask 'What organizational role can I take?'. Around 150 individuals from 30 different institutions have experience and memory of the product of this goodwill, and we are optimistic that many more will be inspired in the future.

\section{ACKNOWLEDGMENTS}

We grateful acknowledge the event's sponsors (Google, IBM, Womenintechnology.co.uk, Shell, Yorkshire Water, Ob- jectivity) who were and remain fundamental to its continued success. BCSWomen members volunteered time and energy towards organisation, abstract reviewing, and managing the day. HEFCE, via the Active Learning in Computing CETL [14] were key in bootstrapping funding. The University of Leeds was generous in its assistance in hosting the first two events, and the University of Cardiff likewise for the 2010 event. We would like to particularly thank Vicky Greaves from Google for all of her help and support.

\section{REFERENCES}

[1] New image for computing. Technical report, ACM: http://www.acm.org/membership/NIC.pdf.

[2] Scholarships: The society of women engineers. WWW: http://societyof womenengineers. swe . org, 2009.

[3] The Google Anita Borg memorial scholarship. WWW: http://www.google.com/anitaborg, 2010.

[4] J. C. Blickenstaff. Women and science careers: leaky pipeline or gender filter? Gender and Education, 17(4):369-386, 2005.

[5] J. Boaler. The development of disciplinary relationships: Knowledge, practice and identity in mathematics classrooms. For the Learning of Mathematics, 22(1):42-47, 2002.

[6] T. Camp. The incredible shrinking pipeline. Communications of the ACM, 40(10):103-110, 1997.

[7] e-Skills UK, BCS, BERR, Intellect. Women in IT scorecard. Technical report, http://www.bcs.org//upload/pdf/scorecard.pdf, 2009.

[8] S. Fincher, M. Petrie, and M. Clark. Computer Science Project Work: Principles and Pragmatics. Springer, 2001.

[9] A. Finkelstein. Computer science 2008: student research conference. WWW: http://www. computingconference.org/, December 2008.

[10] P. Lockwood. "Someone like me can be successful": Do college students need same-gender role models? Psychology of Women Quarterly, 30:36-46, 2006.

[11] C. Magazine. Top 100 CIOs. WWW: http://www.cio.co.uk/cio100/company-name/, 2010.

[12] A. Morgan, J. Quesenberry, and E. Trauth. Exploring the importance of social networks in the it workforce: Experiences with the "boy's club". In AMCIS 2004 Proceedings, 2004.

[13] J. Seely Brown, A. Collins, and P. Duguid. Situated cognition and the nature of learning. Educational Researcher, 18(1):32-42, 1989.

[14] Universities of Durham, Leeds, Leeds Metropolitan, Newcastle. Active learning in computing. WWW: http://www.dur.ac.uk/alic/, 2005-2010.

[15] Unknown. Top 10 internet entrepreneurs. WWW: http:

//hubpages.com/hub/Top-10-young-entrepreneurs, Accessed Jan 2010.

[16] E. Wenger. Communities of Practice: Learning, meaning, and identity. Cambridge University Press, 1998. 